\title{
Damage Control Surgery for the Management of Major Obstetric Hemorrhage: Experience from the Fundación Valle Del Lili, Cali, Colombia
}

\author{
${ }^{1}$ María F Escobar, ${ }^{2}$ Javier A Carvajal, ${ }^{3}$ Juan M Burgos, ${ }^{4}$ Adriana Messa, ${ }^{5}$ Carlos A Ordoñez, ${ }^{6}$ Alberto F García \\ ${ }^{7}$ Marcela Granados, ${ }^{8}$ Angélica M Forero, ${ }^{9}$ José D Casallas, ${ }^{10}$ Laura S Thomas, ${ }^{11}$ Albaro J Nieto
}

\begin{abstract}
Objective: The aim of this case series is to describe the experience of implementing damage control resuscitation (DCR) in patients with major obstetric hemorrhage $(\mathrm{MOH})$ between January 2005 and December 2015 in the Fundación Valle del Lili, Cali, Colombia.
\end{abstract}

Materials and methods: This is a prospective descriptive study of a case series from 108 patients with $\mathrm{MOH}$ who were subjected to DCR. All patients were operated on using a standardized surgical technique in accordance with the institutional protocol.

Results: The median age was 28 years, with a gestational age of 38 weeks. The principal associated diagnosis was severe preeclampsia (in $39 \%$ of cases). A total of 96 patients presented massive postpartum hemorrhage, and $75 \%$ of these cases presented after a cesarean section. In all patients, normal control of bleeding was achieved, $60 \%$ during the first surgical period. The Acute Physiology and Chronic Health Evaluation score was 14 , with an overall mortality of $6.48 \%$, far below the expected mortality according to the clinical severity of these patients.

Conclusion: This study includes the biggest series of pregnant women with $\mathrm{MOH}$, in a critical condition, in whom DCR was used, during which rapid control of bleeding was achieved, associated with a significantly lower mortality than expected.

Keywords: Emergency treatment, Hypovolemic shock, Postpartum hemorrhage, Surgical intensive care.

How to cite this article: Escobar MF, Carvajal JA, Burgos JM, Messa A, Ordoñez CA, García AF, Granados M, Forero AM, Casallas JD, Thomas LS, Nieto AJ. Damage Control Surgery for the Management of Major Obstetric Hemorrhage: Experience from the Fundación Valle Del Lili, Cali, Colombia. Panam J Trauma Crit Care Emerg Surg 2017;6(1):1-7.

Source of support: Nil

Conflict of interest: None

${ }^{1}$ Principal Investigator, ${ }^{2}$ Fellow, ${ }^{3,4}$ Intensivist ${ }^{5,6}$ Trauma and Emergency Surgeon, ${ }^{7}$ Director, ${ }^{8,9}$ Researcher ${ }^{10}$ Student ${ }^{11}$ Gynecologist, Obstetrician, Specialist and Intensivist

1,3,4,8-10Department of Obstetrics and Gynecology, Fundación Clínica Valle del Lili, Cali, Valle del Cauca, Colombia

2,11 Intensive Care Unit, Department of Obstetrics and Gynecology Fundación Clínica Valle del Lili, Cali, Valle del Cauca, Colombia

${ }^{5,6}$ Department of General Surgery, Fundación Clínica Valle del Lili, Cali, Valle del Cauca, Colombia

${ }^{7}$ Department of Intensive Care Unit, Fundación Clínica Valle del Lili, Cali, Valle del Cauca, Colombia

Corresponding Author: María F Escobar, Principal Investigator Department of Obstetrics and Gynecology, Fundación Clínica Valle del Lili, Cali, Valle del Cauca, Colombia, Phone: +3154331584, e-mail: mayaev@hotmail.com

\section{RESUMEN}

Objetivo: El objetivo de esta serie de casos es describir la experiencia de la aplicación de la CCD (Cirugía de control de daños) en pacientes con hemorragia obstétrica mayor (HOM) entre enero del 2005 y diciembre del 2015 en la Fundación Valle del Lili, Cali, Colombia.

Métodos: Estudio descriptivo prospectivo de una serie de casos de 108 pacientes con HOM sometidas a CCD. Todas las pacientes fueron operadas usando una técnica quirúrgica estandarizada, acorde al protocolo institucional.

Resultados: La mediana de edad fue de 28 años, con edad gestacional de 38 semanas. El diagnosticó principal asociado fue pre eclampsia severa (en $39 \%$ de los casos). 96 presentaron hemorragia postparto masiva (HPP) y el $75 \%$ de los casos se presento después de cesárea. En todas las pacientes se logro el control del sangrado, $60 \%$ en el primer tiempo quirúrgico. EI APACHE II promedio fue de 14 con una mortalidad global de $6,48 \%$, muy por debajo de la mortalidad esperada para la severidad clínica de estas pacientes.

Conclusiones: Este estudio incluye la serie más grande de gestantes con HOM en condiciones críticas, en quienes se utilizó $C C D$, con rápido control del sangrado, asociado a una mortalidad considerablemente menor a la esperada.

Palabras Clave: Choque hipovolémico, Cuidados intensivos quirúrgicos, Hemorragia postparto, Tratamiento de urgencia.

\section{INTRODUCTION}

Postpartum hemorrhage (PPH) is the principal cause of extreme maternal morbidity (EMM) and maternal mortality in developing countries, responsible for at least 303,000 deaths per year, a large proportion of which could be preventable with timely and adequate management. ${ }^{1}$ The approach for improving outcomes for this condition includes early recognition of hemodynamic instability, immediate bleeding control, and hemostatic resuscitation. $^{2-4}$

When blood loss volume exceeds $40 \%$ of total blood volume, global hypoxia and multiple organ dysfunctions develop, with metabolic damage in which hypothermia, coagulopathy, and metabolic acidosis are present. In these conditions, the rescue strategy is called damage control resuscitation (DCR). The key components of DCR are hemostatic resuscitation, crystalloid limitation, permissive hypotension, low-volume resuscitation, and damage control surgery (DCS). Damage control surgery can be 
differentiated into four stages: Initial resuscitation, initial laparotomy, resuscitation phase, and definitive surgery (or surgeries). 5,6 There is no level-one evidence to support these four phases and the algorithm was developed as a theory for DCS.

At initial phase of resuscitation, the objective is to aggressively optimize hemodynamic parameters obtaining venous accesses to ensure resuscitation and blood products replacement, which, together with subsequent surgical management, points to the correction of systemic acidosis, hypothermia, and coagulopathy. The laparotomy aims for the rapid control of life-threatening injuries and to uncover evidence of limb exsanguination, persistent hemodynamic instability, appearance of clinical coagulopathy, and installation of other components of the deadly triad. The decision to shorten the surgery must be taken: Packaging with towels and a temporary closure of the abdominal wall, a procedure known as DCS. ${ }^{7,8}$

In the packing process, compresses need to be placed, doubled up on the bleeding surfaces of the abdominal and pelvic cavity, while applying manual compression with temporary closure of the cavity to reduce the surgical time and increase the volume of the cavity. In obstetrics, the decision to use packaging as part of DCS is usually taken after performing the hysterectomy and before the clinical diagnosis of coagulopathy. ${ }^{9,10}$

The third phase (i.e., resuscitation) is performed in the intensive care unit (ICU) to enable rapid correction of metabolic failure in the first 60 hours following the DCS. Finally, in the definitive surgery, the packaging is removed and the definitive correction of injuries not addressed in the first surgery is performed, followed by the closure of the cavity. ${ }^{11}$

Reports of the use of DCR in obstetrics are few. Since the year 1999, published reports include small groups of pregnant patients with bleeding or postcesarean section bleeding or ruptured ectopic pregnancy. ${ }^{12,13}$ The largest previously published cohort of pregnant women includes 28 cases, all of whom received packaging due to uncontrolled bleeding with temporary closure of the abdominal wall, reporting a maternal mortality rate of $35 \% .{ }^{14,15}$

Fundación Valle del Lili (FVL) is a private nonprofit hospital in Cali, Colombia, with an emphasis on the care of high-complexity patients. The High Complexity Unit (UACO) attends obstetric patients. As the FVL is a reference center for the Southwest of Colombia, obstetrics attends patients with serious diseases, which present major obstetric hemorrhage $(\mathrm{MOH})$. This study is a review of the experiences of DCR over the last 10 years in patients (January 2005 to December 2015), with the purpose of sustaining the implementation of this concept for the management of exsanguinating bleeding $(\mathrm{MOH})$ in cases in which conventional measures have not achieved control of the hemorrhage.

\section{MATERIALS AND METHODS}

This is a case series of a cohort followed prospectively from patients with $\mathrm{MOH}$ subjected to DCR in the FVL. The primary source for the information search was the institutional records held at the UACO. The Institutional Ethics Committee approved the protocol. All the patients and their families were informed of the need to use the DCR. The information was collected using an instrument designed for this purpose (institutional database called BD Clinic).

We included all pregnant women who presented $\mathrm{MOH}$ with coagulopathy, acidosis, and/or hypothermia, and who were subjected to DCR in the institution with a protocol including multidisciplinary management (obstetrics, general surgery, and intensive care). The surgical technique used was a variant of that described by Barker et al, ${ }^{16}$ with 8 to 16 compresses. The intestinal loops are protected with a polyethylene cover upon which a layer of towels is placed at the level of the median line where two silicone drains are located, which remove the excess fluid via additional holes in the skin that were made after the initial incision. A new layer of compresses is placed on the drains, which is sealed with a polyester covering and then an adhesive sealant. When the vacuum-pack system is finished, the drains are connected to a reservoir, which is connected to a source of negative pressure (100-110 mm Hg). In some patients, a commercial variant of $\mathrm{VAC}^{\circledR}$ was used, incorporating flexible polyurethane foam which functioned as a drain, with no additional output holes and with a polyester covering sealant connected to the source of negative pressure. ${ }^{17,18}$

Demographic variables were established, including etiology, management, and outcomes. Hypoperfusion was measured using lactic acid (in $\mathrm{mg} / \mathrm{dL}$ ), and the base deficit at the time of diagnosis and of the impact was also measured to provide objective variables. The Acute Physiology and Chronic Health Evaluation score ${ }^{19}$ was used to evaluate the critical condition of the patients in the first 24 hours after the start of the hemorrhage.

The massive transfusion package (MTP) protocol used is preestablished by multidisciplinary consensus in our institution. It is activated and confirmed by phone call to the institutional blood bank when severe hemorrhagic shock is clinically detected (systolic arterial pressure $<90 \mathrm{~mm} \mathrm{Hg}$, cardiac frequency $>105 \mathrm{bpm}$, and evidence of any cause of obstetric bleeding). Early assessment of hemostatic and acid-basic profile, central lab blood count, plasma fibrinogen levels, and blood gas-chemical-hematocrit analyzer is made (i-STAT Handheld, Abbott Inc. Princeton, NJ, USA). A first MTP included three packaged red blood cells (PRBCs) and two fresh frozen plasma (FFP) units, and, if considered, a second package including three PRBCs, two FFP units, and one platelet apheresis unit. 

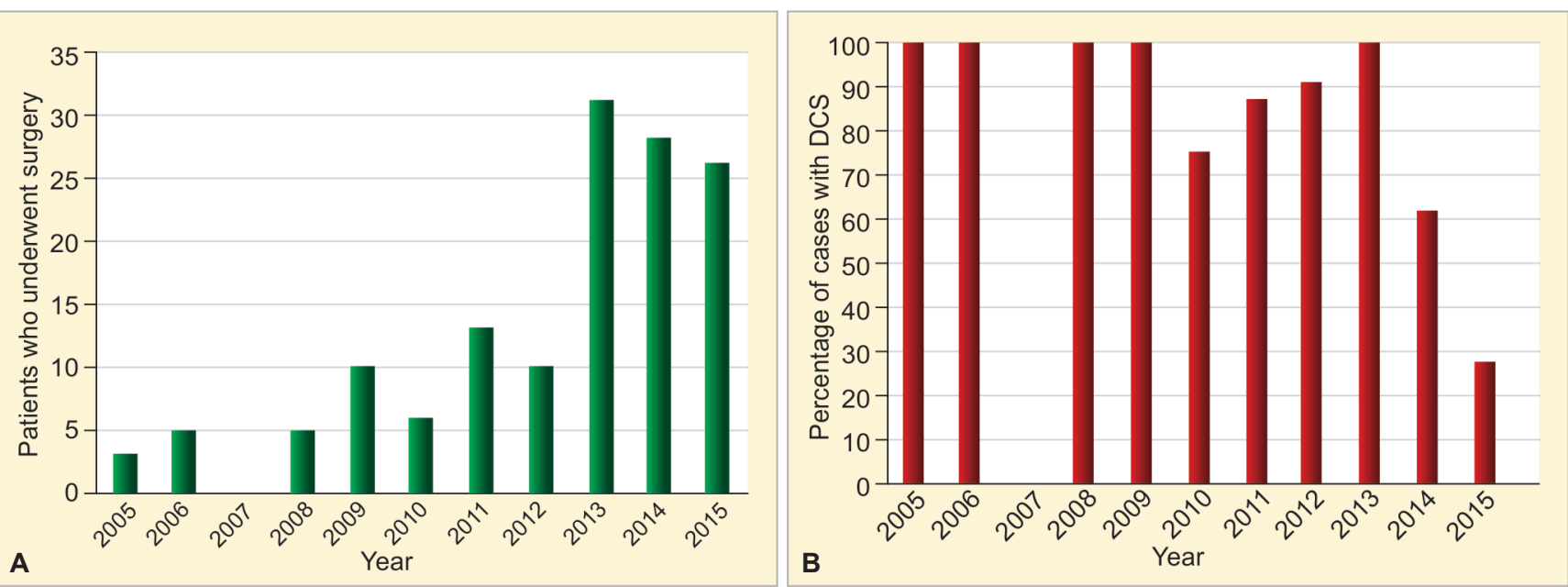

Graphs $1 \mathrm{~A}$ and B: Number and percentage of patients with DCR compared with EMM by MOH

Specific initial assessment on fibrinogen kinetics is primarily based on thrombelastography (TEG $5000^{\circledR}$ thrombelastograph hemostasis analyzer, Haemonetics Corp., Braintree, MA, USA), using $\mathrm{K}$ time and alfa angle and laboratory plasma levels (Clauss method) when possible. If a derangement is detected, a total initial dose of 3 to $4 \mathrm{gm}$ of fibrinogen is assured [administered dose as FFP (750-800 $\mathrm{mg}$ per unit)] and completed as cryoprecipitate (250 $\mathrm{mg}$ per unit) if needed. After dose adjustment, a second TEG and plasmatic fibrinogen is made for control. After this point, successive hemocomponent needing is based on hematology/hemostasis, acid-basic, and clinical criteria.

The analysis of results was carried out using STATA software. Analysis of quantitative variables was performed using nonparametric methods (median and quartiles) and the categorical variables were analyzed using a distribution of frequencies. The APACHE II was divided into two strata taking into account the median of the distribution. In this study, the APACHE II score was used for the stratification of the severity of the patients and also to define the estimated risk of individual in-hospital mortality. Mortality rate was compared with the expected values for patients, which was calculated using the scale. In theory, lower mortality rate obtained with regard to the expected mortality rate means better quality of the service provided.

\section{RESULTS}

In a 10-year period, 108 patients with $\mathrm{MOH}$ were treated using DCR, corresponding to $1.9 \%$ of the total births and $50 \%$ of patients with EMM due to $\mathrm{MOH}$ (number $=215$ ). Graphs 1A and B present behavior of the number and percentage of patients. Population characteristics are described in Table 1.

Age range was 15 to 39 years with a median age of 28 [interquartile range $(\mathrm{IQR})=22-33$ ]. The majority of patients were experiencing their second pregnancy. In 81 cases
(75\%), the bleeding presented after the cesarean section; in 5 cases $(4.6 \%)$, it was due to a ruptured ectopic pregnancy; and in 7 cases $(6.3 \%)$, the bleeding was postabortion.

The basic causes of bleeding that indicated DCR in cases of PPH or postcesarean section according to the " $4 \mathrm{~T}$ " mnemonic are reported in Table 2. About $64 \%$ of

Table 1: Characteristics of the patients subjected to DCR in the FVL between January 2005 and December 2015

\begin{tabular}{|c|c|}
\hline Variable & Value \\
\hline Age $\left(\right.$ years) ${ }^{a}$ & $28(22-33)$ \\
\hline Gravity $^{a}$ & $2(1-3)$ \\
\hline Gestational age (weeks) ${ }^{a}$ & $36(30-38)$ \\
\hline \multicolumn{2}{|c|}{ Associated clinical diagnoses (number of cases/\%): } \\
\hline - Preeclampsia & $43(39.8 \%)$ \\
\hline - HELLP & $22(20.4 \%)$ \\
\hline - Panmetritis & $22(20.4 \%)$ \\
\hline - Eclampsia & $9(8.3 \%)$ \\
\hline - Amniotic liquid embolism & $9(8.3 \%)$ \\
\hline - Other causes & $3(28 \%)$ \\
\hline \multicolumn{2}{|c|}{$\begin{array}{l}\text { Method of termination of the pregnancy (number } \\
\text { of cases } / \% \text { ): }\end{array}$} \\
\hline - Ectopic pregnancy & $5(4.6 \%)$ \\
\hline - Abortion & $7(6.5 \%)$ \\
\hline - Live vaginal delivery & $15(13.8 \%)$ \\
\hline - Cesarean section & $81(75.0 \%)$ \\
\hline \multicolumn{2}{|c|}{$\begin{array}{l}\text { Place of birth or termination of the pregnancy } \\
\text { (number of cases } / \% \text { ): }\end{array}$} \\
\hline - FVL & $91(84.2 \%)$ \\
\hline - Other institutions & $17(15.7 \%)$ \\
\hline Number of days in the $\mathrm{ICU}^{\mathrm{a}}$ & $13(8-18)$ \\
\hline Number of days in the UACO & $12(8-19)$ \\
\hline
\end{tabular}

${ }^{a}$ Median (IQR); HELLP: Hemolysis, elevated liver enzyme levels, and low platelet levels

Table 2: Basic causes of bleeding in HPP, according to the 4T mnemonic

\begin{tabular}{ll}
\hline Basic causes of PPH & Number (\%) \\
\hline Tone & $67(70)$ \\
Tissue & $15(15)$ \\
Trauma & $8(9)$ \\
Thrombin & $6(6)$ \\
\hline
\end{tabular}


the patients received active management with oxytocin during the third period of labor. During the bleeding episode, management was oxytocin, methylergometrine, and misoprostol in $42 \%$ of cases. Before the DCR, attempts were made with conservative surgery using the B-lynch technique in six patients and vascular ligation in four patients.

In 91 patients, $84.3 \%$ received the DCR in our hospital and 17 cases $(15.7 \%)$ received the DCR at the referral hospital; the average time from the start of the $\mathrm{MOH}$ to the DCR was less than 1 hour in $73.1 \%$ of patients (79), less than 12 hours for $19.4 \%$ of patients (21), and greater than 12 hours in $7.5 \%$ of patients (8). At the beginning of DCR, the median temperature of the patients was $36.5^{\circ} \mathrm{C}(\mathrm{IQR}=$ 36-37). The median of the coagulation time for PT was 14.8 seconds (IQR = 12.7-17.7), 36.8 seconds for the PTT (IQR $=32-42)$, and 250 for fibrinogen (IQR $=160-408)$. Platelet count was 96,000 (IQR = 50,000-127,000), with excess base levels of $-6(\mathrm{IQR}=-4$ to -27.4$)$ and lactic acid of $2(\mathrm{IQR}=$ 1.3-14.5) (maximum value 14.5 and minimum value 0.4 ).

Pelvic packaging was carried out with 14 towels (IQR $=8-16)$. In $97 \%$ of the patients, control of bleeding was achieved; in $60 \%$ of patients (65), this was their first surgery; and $40 \%$ of the patients bled again due to coagulopathy at the time of the first unpacking, which required a second packaging in 38 patients (35.4\%) and a third packaging in $5(4.6 \%)$ of the cases. The review time from the first intervention was 48 hours (IQR $=42-72$ ) in $81 \%$ of patients. In less than 24 hours, a second look were required in $16(14 \%)$ of patients with persistent bleeding (Table 3).

All patients were managed in the ICU with an average stay of 13 days (IQR $=8-18$ ), with high transfusion requirements according to the MTP protocol. Transfusion requirements that include an average of 5 units of red blood cells were transferred: 6 units of plasma, 4.5 of platelet apheresis, and 10 units of cryoprecipitate. The most frequent complications were surgical wound infections $(28.7 \%)$, intra-abdominal abscesses $(20.3 \%)$, evisceration $(10.1 \%)$, and abdominal compartment syndrome (ACS) $(9.26 \%$ ) (Table 4$)$. In the ACS cases, the crystalloids used were ringer lactate, with an accumulated balance of $3455(\mathrm{IQR}=2770-4904)$ at the DCS time.

The APACHE II score in the first 24 hours postsurgery was obtained in all cases. The median was 14 (IQR = 9-18); 58 patients (53.7\%) had 14 points or less on the APACHE II score and none died; 50 patients (46.2\%) had more than 14 points, and 7 (50\% of the group) patients died. Expected mortality according to the intervals of the APACHE II was 14 vs $6.5 \%$ of the observed mortality. The categorization of the patients according to APACHE II and the differences between observed mortality compared with expected mortality, according to this APACHE II score, is presented in Graphs 2A and B.
Table 3: Characteristics of the DCR

\begin{tabular}{ll}
\hline Variable & Value \\
\hline Place of the first DCR (number of cases/\%) & \\
• FVL & $91(84.3 \%)$ \\
• Another institution & $17(15.7 \%)$ \\
Total abdominal hysterectomy (number of cases) & $88(81.5 \%)$ \\
Subtotal hysterectomy (number of cases) & $20(18.5 \%)$ \\
Number of compresses used in the first packaging & $14(8-16)$ \\
Time between surgeries and DCR & \\
• $<1$ hour & $79(73.0 \%)$ \\
- $1-12$ hours & $21(19.0 \%)$ \\
• Greater than 12 hours & $8(8.0 \%)$ \\
Time between DCR and the first reintervention & $48(42-72)$
\end{tabular}

(hours) $^{a}$

Number of DCR before the hemorrhage was controlled

- 1

- 2

- 3

$65(60.0 \%)$

$38(35.4 \%)$

$5(4.6 \%)$

$37(34.2 \%)$

Patients requiring vasoactive supports

$2(1.8 \%)$

Patients requiring renal replacement therapy

Number of hemoderivatives transfused during the hospitalization (units):

- Packed red blood cells ${ }^{a}$

$5(3-9)$

- Frozen fresh plasma ${ }^{a}$

$6(4-10)$

- Units of platelets ${ }^{a}$

- Units of cryoprecipitate ${ }^{a}$

$4.5(1-12)$

$10(6-12)$

$16(14.0 \%)$

$17(15.0 \%)$

Pelvic embolization

- 6 cases before the first surgery due to acretism

- 10 cases between 3 and 24 hours after the first surgery at our institution

- 1 case after 3 days of the first surgery in the other institution

Vascular ligature

$4(3.7 \%)$

Administration of coagulation factors

$8(7.4 \%)$

- 4 cases of factor VII recombinant

- 4 cases of II, VII, IX, X concentrated factors

Administration of topical thrombin

$5(4.6 \%)$

Vaginal packing

1 vaginal outbreak with deferred plastic surgery

${ }^{\mathrm{a}}$ Median (IQR)

Table 4: Frequency of complications associated with the DCR

\begin{tabular}{ll}
\hline Complication & Number (\%) \\
\hline Infection of the surgical wound & $31(28.6)$ \\
Intra-abdominal abscesses & $20(20.3)$ \\
3 pericardiocentesis & \\
17 surgical drainages & \\
2 open vaginal vault drainage & \\
Evisceration & $11(10.1)$ \\
Abdominal compartment & $10(9.3)$ \\
Pneumonia & $4(3.7)$ \\
Pulmonary thromboembolism & $3(2.8)$ \\
Intestinal lesion & $2(1.8)$ \\
Gastric fistula (in relation to a projectile wound) & $1(0.9)$ \\
Ureter injury (relative to TAH) & $1(0.9)$ \\
\hline
\end{tabular}

$\mathrm{TAH}$ : Total abdominal hysterectomy 

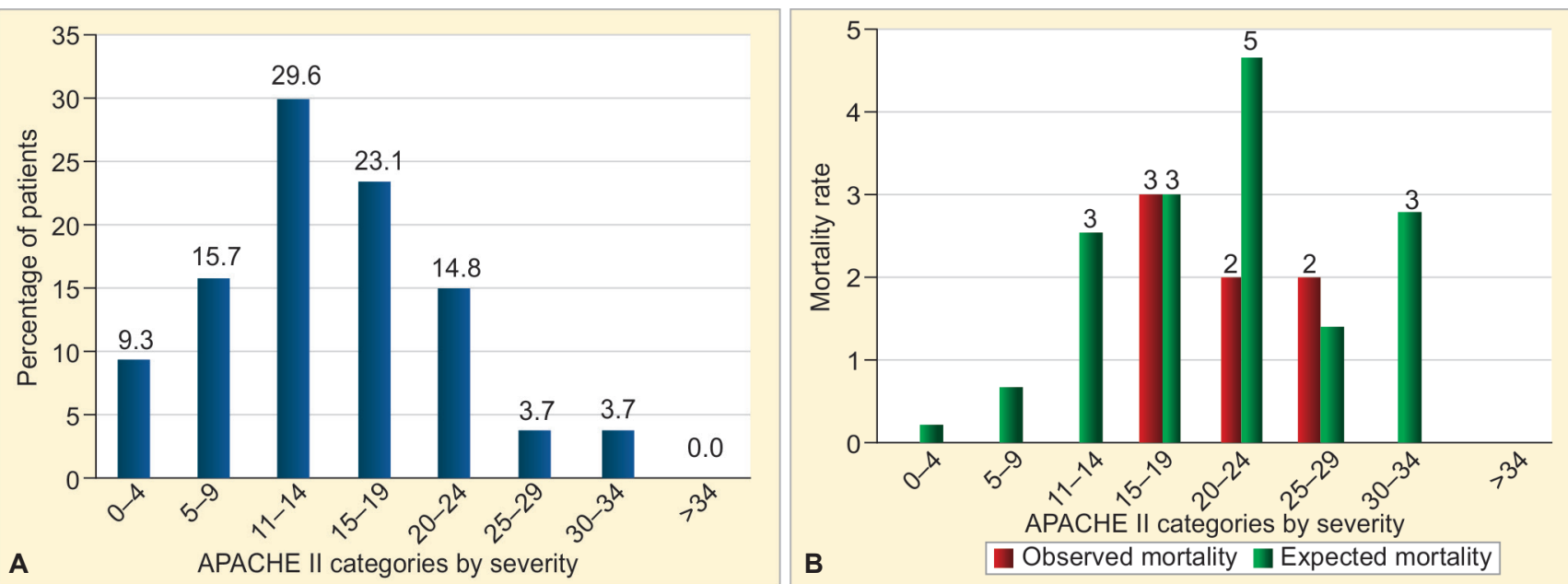

Graphs 2A and B: Categorization of the patients according to the APACHE II score and comparison of observed and expected mortality by category

The principal cause of death was associated with hypovolemic shock and coagulopathy in four patients $(3 \%)$; one case of organ failure secondary to acute respiratory distress syndrome by infection with AH1N1; one case of severe complications related to sickle cell anemia; and one case of amniotic fluid embolism. The cases handled with DCR corresponded to $2.01 \%$ of total births and to $50.23 \%$ of the $\mathrm{MOH}$ cases handled between January 2005 and December 2015.

\section{DISCUSSION}

Hypovolemic shock is directly responsible for maternal deaths due to obstetric hemorrhage. The possibility of complications or death is proportional to the depth and duration of shock and development of hypothermia, acidosis, and coagulopathy. ${ }^{18,20}$ In these cases, the application of conventional measures to control bleeding is ineffective and probability of survival seems to increase with the implementation of DCR. ${ }^{20}$

This study contains the largest number of cases described in the literature so far for DCR in severely compromised obstetric patients. The high frequency of DCR in our institution is explained by the critical condition of patients with $\mathrm{MOH}$.

An early indication of DCR leads to a better result, given the fact that the mortality increases if the decision to use DCR is taken after a first, initial surgery. ${ }^{21} \mathrm{In} \mathrm{MOH}$, the decision to use DCR is taken, in most cases, after the completion of the abdominal hysterectomy, whose results are dependent on the aggressiveness of the decisionmaking. This concept is called the "surgeon factor" and is an influential determinant of maternal mortality, considering that the average time to define specific surgical interventions for their control, after the start of bleeding in $\mathrm{MOH}$, is 60 minutes. ${ }^{21,22}$
In our study, $88.8 \%$ (96) of patients required an abdominal hysterectomy; in $5.6 \%$ of cases, this was attempted with conservative management techniques, including B-lynch-type surgery; and 3.7\% required ligatures for vascular disorders. The low incidence of conservative surgeries is attributable to clinical compromise of patients. ${ }^{23}$

The surgical control of bleeding is the most important aspect of DCS. About 35\% of cases required two surgical interventions (repacking) in order to obtain an effective control of bleeding, and 5\% required three procedures based in persistent coagulopathy. Although optimum time to remove the packaging depends on clinical condition of each patient, in trauma patients, optimum time is between 48 and 72 hours, with a more frequent recurrence of bleeding being correlated with shorter times and an increase in the infection risk with longer times. ${ }^{7,20}$

The patients that required this type of intervention were critically ill pregnant women with an average APACHE II score of 14 . The alteration of perfusion parameters in $100 \%$ of cases was reflected in the levels of lactic acid (greater than 2.5) and base excess (less than -6). Even so, the mortality was $6.48 \%$, which is much lower than that reported in previous studies ${ }^{12,15}$ and is also lower than predicted for severity levels of APACHE II close to $40 \%$, shown in Graphs $2 \mathrm{~A}$ and B. These results may be related to a management protocol along with standard surgical techniques, early admission to ICU, hemostatic resuscitation with availability of early packaging, with massive transfusion, aggressive handling of hypothermia, control of acidosis, and the availability of other interventions to control hemorrhage (Flow Chart 1). We believe that DCR plays an essential role because it allows more time for action to be able to complete all of these therapies, allowing resuscitation to be addressed much earlier.

One of the obstacles to performing DCR is the fear of the associated major complications. In this series of 
Flow Chart 1: Institutional protocol (algorithm) for $\mathrm{MOH}$ management and DCR

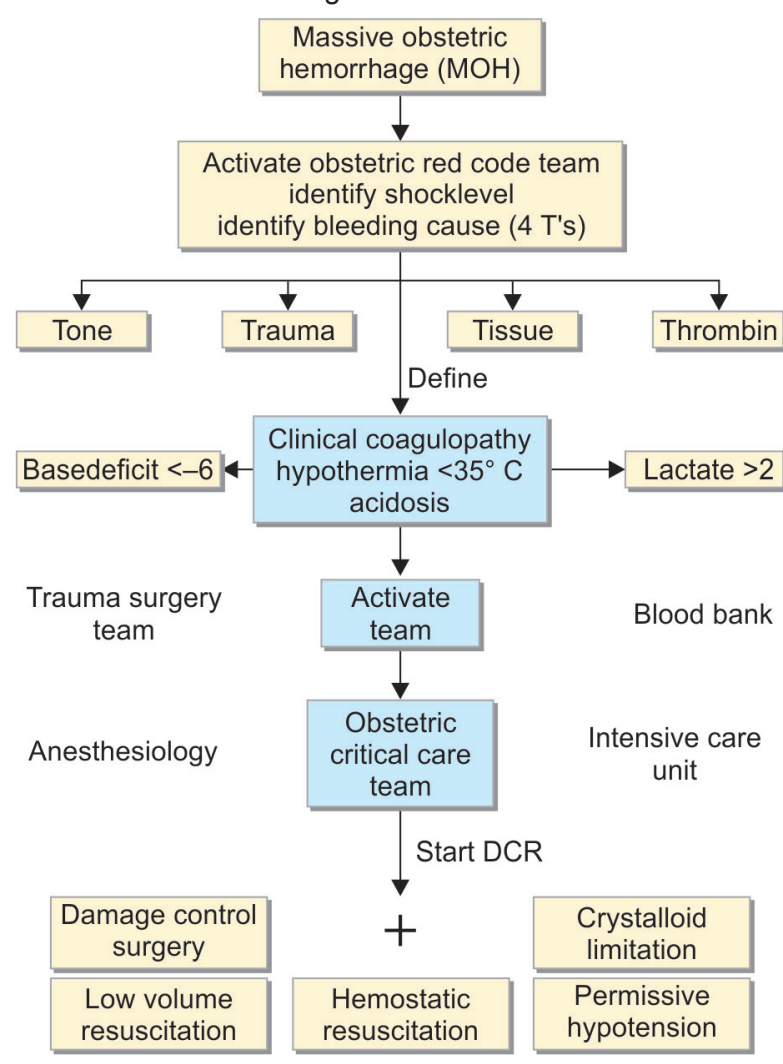

cases, infections in the skin (28.7\%) and intra-abdominal infections $(20 \%)$ were the most frequent complications, which may be related to technical conditions of emergency surgery in contact with the genitourinary tract, and the presence of hypoperfusion at the start of the procedure. We reported compartment syndrome in $9.2 \%$ of patients, emphasizing the importance of controlling intra-abdominal pressure in the postoperative period. None of the deaths in this study were related to complications associated with the use of DCR, nor were there any reported complications related to gastrointestinal fistulas. ${ }^{24}$ This is probably due to the fact that, in the surgical management of $\mathrm{PPH}$, bowel injuries are rare.

Realization of a large number of DCR procedures not only positively influences surgeon expertise, but also lowers the threshold for its execution, leading to the possibility of overusing this technique. High APACHE II scores, the presence of coagulopathy and hypoperfusion, and the volume of transfused blood components suggest that, in most cases, the procedure was indicated.

\section{CONCLUSION}

This study represents the largest number of critically ill pregnant women with $\mathrm{MOH}$, in whom the DCR was used to control bleeding and which was successful in $97 \%$ of cases.
As a catastrophic event, the patient with $\mathrm{MOH}$ must be handled in centers that are able to handle high-complexity cases and which have the equipment, installations, and expertise that would allow them to perform DCR as a rescue strategy in those patients who are experiencing hypothermia, acidosis, and coagulopathy. Adequate preparation of the health services and the development of, and adherence to, a management protocol has been shown to improve the results. ${ }^{25}$ With these reported results, the DCR has proved to be applicable in obstetrics, and it should be included as a final rescue strategy in the management algorithms for $\mathrm{MOH}$.

\section{REFERENCES}

1. Alkema L, Chou D, Hogan D, Zhang S, Moller A, Allison G, Ma Fat D, Boerma T, Temmerman M, Mathers C, et al. Global, regional, and national levels and trends in maternal mortality between 1990 and 2015, with scenario-based projections to 2030: a systematic analysis by the UN Maternal Mortality Estimation Inter-Agency Group. Lancet 2015;387(10017):462-474.

2. Mahutte NG, Murphy-Kaulbeck L, Le Q, Solomon J, Benjamin A, Boyd ME. Obstetric admissions to the intensive care unit. Obstet Gynecol 1999 Aug;94(2):263-266.

3. Santoso JT, Saunders BA, Grosshart K. Massive blood loss and transfusión in obstetrics and gynecology. Obstet Gynecol Surv 2005 Dec;60(12):827-837.

4. Sinha R, Roxby D, Bersten A. Experience with a massive transfusion protocol in the management of massive haemorrhage. Transfus Med 2013 Apr;23(2):108-113.

5. Braslow B. Damage control in abdominal trauma. Contemp Surg 2006;62:65-74.

6. Teixeira PG,Salim A, Inaba K, Brown C, BrowderT,Margulies D, Demetriades D. A prospective look at the current state of open abdomens. Am Surg 2008 Oct;74(10):891-897.

7. Ordoñez C, Pino L, Badiel M, Sanchez A, Loaiza J, Ramirez O, Rosso F, García A, Granados M, Ospina G, et al. The 123 approach to abdominal packing. World J Surg 2012 Dec;36(12): 2761-276.

8. Barker DE, Kaufman HJ, Smith LA, Ciraulo Dl, Richart CL, Burns RP. Vacuum pack technique of temporary abdominal closure. A 7 year experience with 112 patients. J Trauma 2000 Feb;48(2):201-206.

9. Dildy GA, Scott JR, Saffer CS, Belfort MA. An effective pressure pack for severe pelvic hemorrhage. Obstet Gynecol 2006 Nov;108(5):1222-1226.

10. Farag GE, Ray S, Ferguson A. Surgical packing as a means of controlling massive haemorrhage in association with advanced abdominal pregnancy. Eur J Obset Gynecol Reprod Biol 2003 Jul;109(1):106-107.

11. Awonuga AO, Merhi ZO, Khulpateea N. Abdominal packing for intractable obstetrical and gynecologic hemorrhage. Int J Gynecol Obstet 2006 May;93(2):160-163.

12. Escobar MF, García A, Fonseca J, Herrera E, Guerrero J. Cirugía de control de daños: Un concepto aplicable en ginecología y obstetricia. Colombia Méd 2005;36(2):110-114.

13. Griggs C, Butler K. Damage control and the open abdomen: challenges for the nonsurgical intensivist. J Intensive Care Med 2016 Oct;31(9):567-576.

14. Demetriades D. Total management of the open abdomen. Int Wound J 2012 Aug;9(Suppl 1):17-24. 
15. García H. Impacto de la cirugía de control de daños en las emergencias hemorrágicas intraabdominales ginecológicas. Rev Arg Cirug 2008;94(1-2):29-28.

16. Brock WB, Barker DE, Burns RP. Temporary closure of open abdominal wounds: the vacuum-pack. Am Surg 1995 Jan;61(1):30-35.

17. Carlson GL, Patrick H, Amin AI, McPherson G, MacLennan G, Afolabi E, Mowatt G, Campbell B. Management of the open abdomen: a national study of clinical outcome and safety of negative pressure wound therapy. Ann Surg 2013 Jun;257(6):1154-1159.

18. Martini WZ, Pusateri A, Uscilowicz JM, Delgado AV, Holcomb JB. Independent contributions of hypothermia and acidosis to coagulopathy in swine. J Trauma 2005 May;58(5):1002-1009.

19. Knaus WA, Draper EA, Wagner DP, Zimmerman JE. APACHE II: a severity of disease classification system. Crit Care Med 1985 Oct;13(10):818-829.

20. Ferrara A, MacArtur JD, Wright M, Modlin IM, McMillen MA. Hypothermia and acidosis worsen coagulopathy in the patient requiring massive transfusion. Am J Surg 1990 Nov;160(5): 515-518.

21. Lamb CM, MacGoey P, Navarro AP, Brooks AJ. Damage control surgery in the era of damage control resuscitation. Br J Anaesth 2014 Aug;113(2):242-249.

22. Centre for Maternal and Child Enquiries (CMACE). Saving Mothers' Lives: reviewing maternal deaths to make motherhood safer: 2006-08. The Eighth Report on Confidential Enquiries into Maternal Deaths in the United Kingdom. BJOG 2011;118(Suppl 1):1-203.

23. Parazzini F, Ricci E, Cipriani S, Chiaffarino F, Bortolus R, Chiantera V, Bulfoni G. Temporal trends and determinants of peripartum hysterectomy in Lombardy, Northern Italy, 1996-2010. Arch Obstet Gynecol 2013 Feb;287(2):223-228.

24. Demetriades D, Salim A. Management of the open abdomen. Surg Clin North 2014 Feb;94(1):131-153.

25. Girard T, Manfred M, Schlembach D. New approaches to obstetric hemorrhage: the postpartum hemorrhage consensus algorithm. Curr Opin Anaesthesiol 2014;27(3): 267-274. 